DOI: http://doi.org/10.21698/simi.2018.fp47

\title{
INTERDISCIPLINARY STUDY REGARDING THE COLOIDAL SILVER SOLUTIONS EFFECT ON MOMORDICA CHARANTIA L. DEVELOPMENT
}

\author{
Adriana Bira ${ }^{1,3}, \underline{\text { Zoltán Marosy }}^{2}{ }_{2}$ Cristian Ion $^{3}$ \\ ${ }^{1}$ Hofigal Export Import SA, 2 Intrarea Serelor Street, district 4, Bucharest, \\ adrianaflorinabira@yahoo.com, Romania \\ ${ }^{2}$ Ecological University of Bucharest, Bucharest, 1G Vasile Milea Boulevard, district 6, \\ Bucharest, marosy.zoltan@gmail.com, Romania \\ ${ }^{3}$ University of Bucharest, Faculty of Physic, Doctoral School of Biophysics and Medical \\ Physics, 405 Atomistilor Street, Bucharest-Măgurele, alexandru.cristianion@yahoo.com, \\ Romania
}

\begin{abstract}
In the $21^{\text {st }}$ century the world faces ecological problems due to the industrialization. One of these issues may be intensive agriculture. The next study reflects the attempt to use a natural means compounds in organic farming. Considering the antibacterial capacity of the coloidal silver solutions was born the idea of using it in organic farming for medical plants development.

Over the course of several years, the observations made have favored the balance to lower concentrations of colloidal silver water solutions.

During this study was observed that the plants were more healthy and the production and the quality of the fruits was also modiffyed.

The plant specie of Momordica charantia L. was chosen for its high interest in its effects. The fruit being used in alternative medicine, also being called „natural insulin”. The seeds used in the experiment were organic certified and were obtained from already acclimatized plants. The experiment unfolding in partially protected environment on an area of about 400 square meters.

This paper highlights the effects of seeds treatament and watering treatment with 3 different concentations (5 ppm, $15 \mathrm{ppm}$ and $30 \mathrm{ppm}$ ) of colloidal silver watter solutions on the development of Momordica charantia L. plants. It is worth mentioning that in previous studies these concentrations attracted the most attention. The most favorable results could be seen in plants treated with colloidal silver solution at the higher concentrations.The Momordica charantia L. plants being obtained by using organic farming method, this study can reflect an inovative method of organic fertilization.
\end{abstract}

Keywords: colloidal silver, Momordica charantia L., organic farming

\section{Introduction}

Colloidal silver contains a suspension of silver nanoparticles in liquid solution. The qualitty of a colloidal solution it is determinated by the dimension and the concentration of the silver particles.

Silver nanoparticles (AgNPs) were prepared in aqueous colloidal dispersions by reducing $\mathrm{Ag}^{+}$with glucose in alkaline medium. 


\section{INTERNATIONAL SYMPOSIUM "THE ENVIRONMENT AND THE INDUSTRY", SIMI 2018, PROCEEDINGS BOOK}

The company uses Momordica charantia L. to produce food supplements with a real economic success, so it is very important for it to be produced in an eco-friendly way and to be of a good quality.

After applying successive treatments with colloidal silver water solutions, from seed hydration to the end of the biocycle, no silver compounds were found in chemical structure of plants. During the experiment, germination, plant growth, fructification, and mineral content were pursued.

For three consecutive years 2016, 2017 and 2018 the experiment was repeated, the results being similar in terms of plant quality.

\section{Materials and Methods}

On each trawl of approximately 100 square meters sowed 2 rows with a number of 71 nests per row, and each nest was sown with 3 seeds of Momordica charantia L. organic certified. Insisting we have 142 nests on each trawl and a total of 426 seeds sown properly.

The seeds sown in the first 3 trawls were kept hydrated for 2 hours in a colloidal silver water solution with a suspension of $5 \mathrm{ppm}$ and then another 22 hours in plain potable water at a temperature of about 45 degrees Celsius.

Seeds sowed in the control trawl as a control were kept hydrated in heated water at about 45 degrees Celsius for 24 hours after being seeded in the field.

After seed drilling in the field, 3 treatments with aqueous colloidal silver solutions were performed of private origin (Aqua Nano 2018 ).

The observations have been made for three consecutive years.

Although the action of each element in the plant body manifests only in interdependence with other elements, it can be shown that the physiological role of the different anions and cations is appreciated by their participation in the functional systems of the cell and the specific functions they exercise in normal, inadequate or excess doses. Green plants predominantly absorb mineral substances, of which organic substances are synthesized by chlorophyll assimilation.

Plant mineral nutrition is a physiological process of supplying plants with nutrients. Green plants predominantly absorb mineral substances of which organic substances are synthesized by chlorophyll assimilation.

Laboratory analyzes for the mineral content were performed during peak harvest by the atomic absorption method. For laboratory analyses we made plant sampling (dried fruits) from each study trawls, V1, V2, V3 (treated with 3 different concentations, 5 ppm, 15 ppm and $30 \mathrm{ppm}$ ) of colloidal silver water solutions and V4 named MARTOR representing the control (untreated).

Atomic absorption spectrometry can be defined as a method for determining the concentration of an element in a sample by measuring radiation absorption in atomic vapor produced by the sample at a specific wavelength and characteristic of the element to be studied. Obtaining a population of free atoms is one of the main functions of atomic absorption devices. It can be done by analyzing the sample in the flame or electrothermal in the graphite furnace (Nitech 2018).

The flame occurs as a result of a combustion process involving a fuel (acetylene) and an oxidant (air or nitrous oxide in the case of refractories). The flame is a source of free atoms and at the same time a space in which they are continuously similar to a cuvette of UV-VIS molecular absorption spectrometry (Nitech 2018). 


\section{INTERNATIONAL SYMPOSIUM "THE ENVIRONMENT AND THE INDUSTRY", SIMI 2018, PROCEEDINGS BOOK}

The used device was an absorbtion and emission spectrometer AVANTA PM - air acetylene - flame equipped with computer and cathodic lamp for each element. The samples have been suposed to $\mathrm{HNO}_{3}, \mathrm{H}_{2} \mathrm{O}_{2}$, and $\mathrm{HCl}$ mineralization (Council of Europe 2010), using an under pressure Berghof-MWS-Microwave digestion apparatus (Popescu et al 2011, Popescu et al 2017, Ionescu et al 2014).

\section{Results and Discussion}

The mineral content influences the good development of the plants. (Pennazio 2005, Hans et al 2015) An optimal content determines their correct development. The analyses made by atomic absorption spectrometry on dried fruits, highlighted the most important compounds for plant development.

Calcium is the most important element for root development. High calcium content stimulates mitochondrial biosynthesis and regulates the elasticity of cell walls, so it favours the stretching and division of the cells. (Shapoval et al 2011)

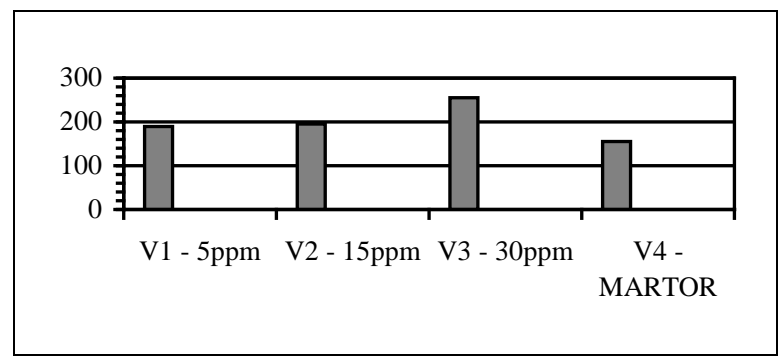

Figure 1. Calcium content in the dried fruits [mg/100g]

Analysing the calcium content from plant dried fruits, we observe in Figure 1 that the samples from V3 trawl has the best content compared with those of V1 and V2 and with control plants from V4.

Magnesium is indispensable in the process of chlorophyll formation in plants as well as in the synthesis of proteins, carbohydrates and lipids. It can also be considered an enzyme activator for plant breeding.

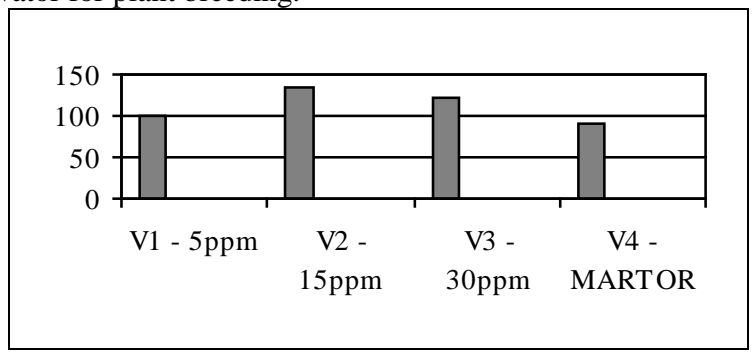

Figure 2. Magnesium content in the dried fruits [mg/100g]

In the Figure 2 we observed that the best magnesium content was for V2 compared with V1 and V2 plant samples and with V4. 


\section{INTERNATIONAL SYMPOSIUM "THE ENVIRONMENT AND THE INDUSTRY", \\ SIMI 2018, PROCEEDINGS BOOK}

Potassium is a stimulant in plant physiological processes, regulates the intensity of photosynthesis, nitrogen metabolism and vitamin synthesis. This element influences plants ability to absorb water and increases resistance to frost and drought.

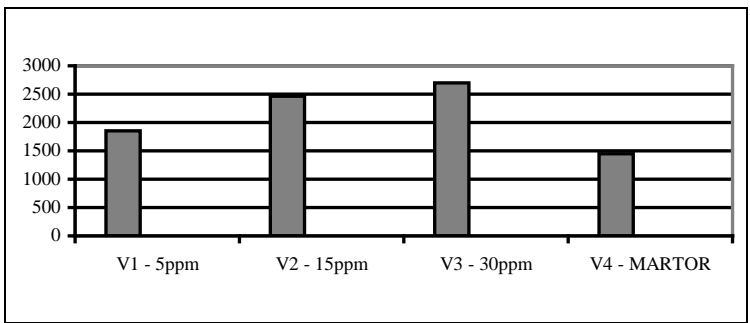

Figure 3. Potassium content in the dried fruits [mg/100g]

In the case of potassium content, we observe that the V3 samples have the best values compared with those of V1, V2 and with V4 (Figure 3)

Manganese is important for plant growth because it activates many enzymes necessary for the formation of vitamins and reduces the content of nitrates absorbed by the plants.

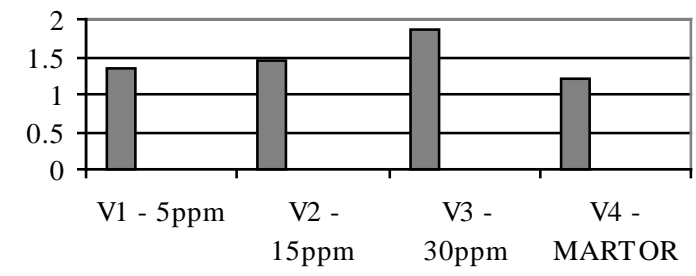

Figure 4. Manganese content in the dried fruits [mg/100g]

Manganese has a significant value at V3 samples, compared with V1, V2 and with V4 (Figure 4).

Iron is absorbed by plants through the root system as ferrous and ferric salts. This macronutrient influences photosynthesis, nitrogen metabolism and biosynthesis of carotenoid and chlorophyll pigments. It is very important because the iron deficiency slows plant growth. (Volker \& Gabriel 2011) 


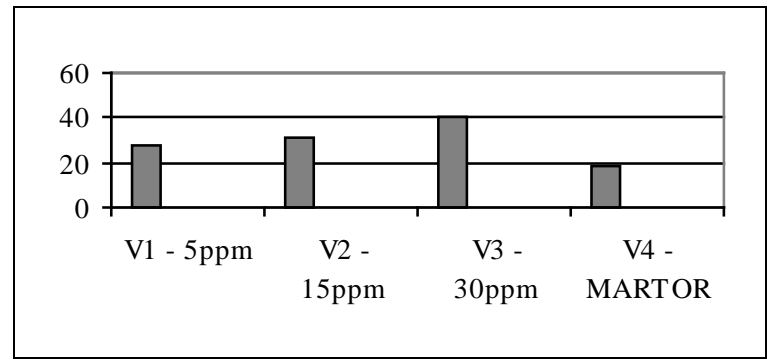

Figure 5. Iron content in the dried fruits [mg/100g]

This important plant nutrient, iron, has the best value at V3 treated plants compared with V1 and V2 plants and with untreated ones V4 as it was observed in Figure 5.

Zinc is very important for plant growth and development, fertilization, increased frost and drought resistance, nitrogen fixation and chlorophyll synthesis.

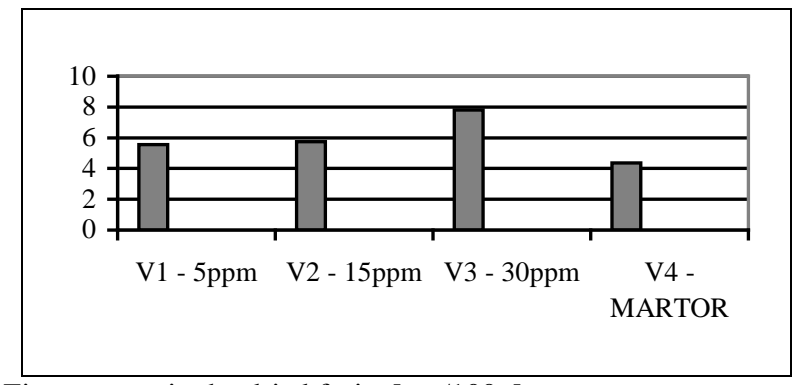

Figure 6. Zinc content in the dried fruits [mg/100g]

The zinc value was significant increased, as we observe in Figure 6 and the best value was obtained at V3 samples compared with V1, V2 and with V4.

We also studied quantitative differences between fruit harvested from each study trawl, treated and untreated ones in Figure 7.

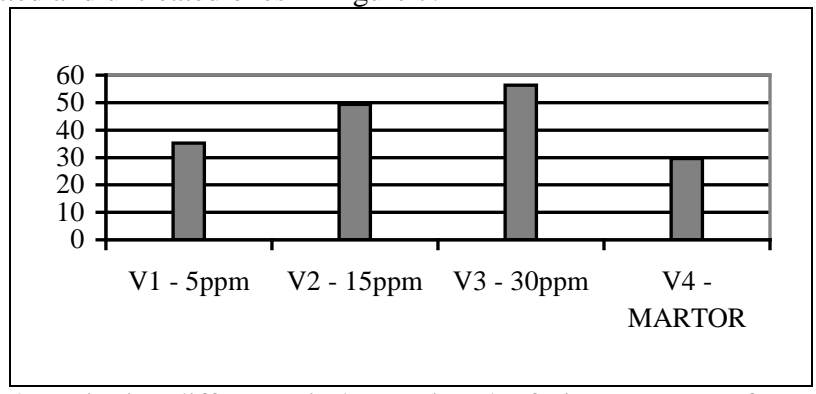

Figure 7. Quantitative difference in harvesting the fruit on an area of approximately 100 square meters for 5 successive weighing [Kg] 


\section{INTERNATIONAL SYMPOSIUM "THE ENVIRONMENT AND THE INDUSTRY", SIMI 2018, PROCEEDINGS BOOK}

Comparing the fruit quantities from each 100 square from each studied trawl, we conclude that was obtained a significant value for V3 sample compared with V1 and V2 and all of them with V4 - untreated trawl.

We also made a germination study, between all of the sampling treated and untreated, used for planting in nests on each studied trawl, V1, V2, V3 and V4.

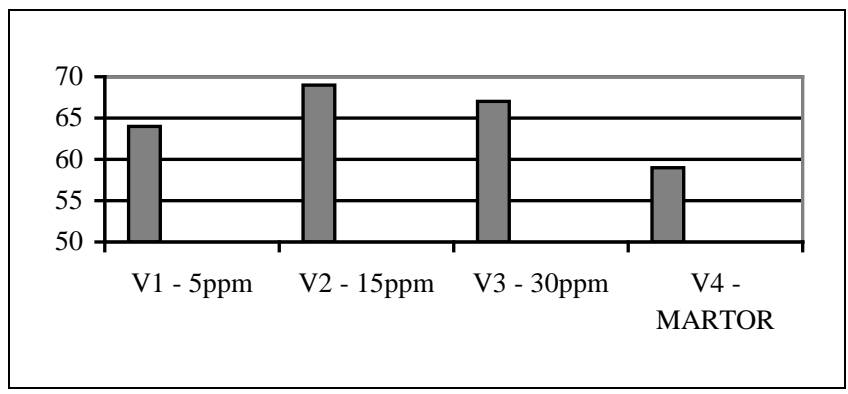

Figure 8. Seeds germination in the field (\%)

We observe in Figure 8, that the best germination value, as percentage, was for V2 trawl, around $70 \%$ compared with V3 aproximate $65 \%$, V1 less than $65 \%$ and V4 untrated less than $60 \%$.

From the below images (Figure 9, Figure 10) we can observe consistent growth differences betwen the control plants (untreated) - V4 named MARTOR and the sample plants (treated with a solution having a silver concentration of $30 \mathrm{ppm}$ ) -V3.

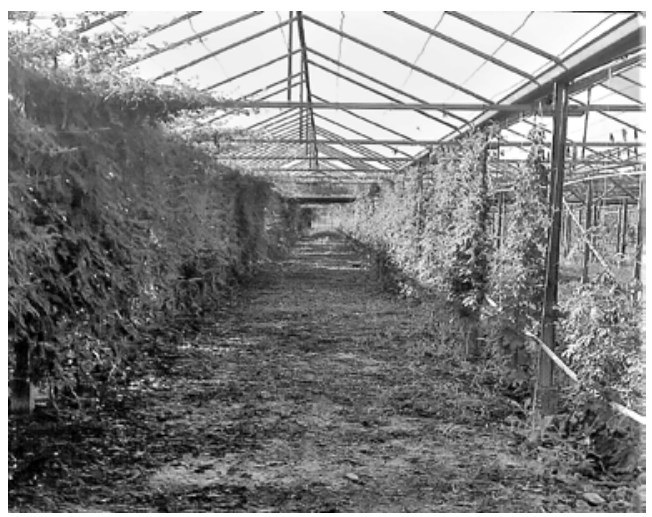

Figure 9. Momordica charantia L. V4 - MARTOR (the weakest results) 


\section{INTERNATIONAL SYMPOSIUM "THE ENVIRONMENT AND THE INDUSTRY", SIMI 2018, PROCEEDINGS BOOK}

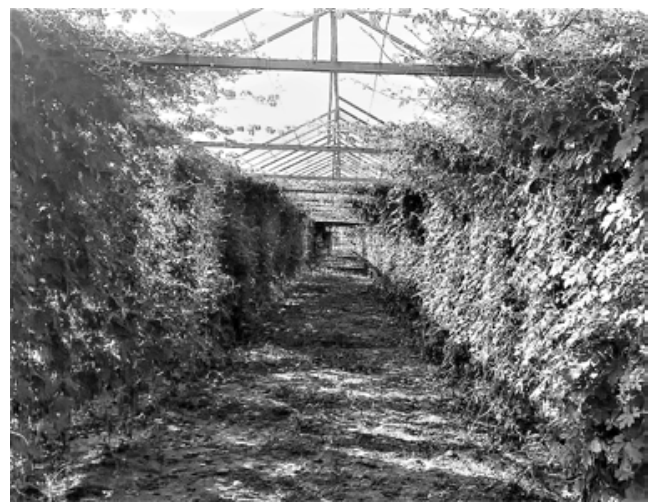

Figure 10. Momordica charantia L. V3 - 30 ppm (the best results)

The results were favourable in the case of colloidal silver aqueous solutions with higher silver concentrations and this aspect is important for Momordica charantia L. development, which has a great economic importance. Therefore, the growth of production in the cultivation process is being pursued, in this case the fruit of the plant is very much used. It is therefore intended to obtain as large quantities as possible.

\section{Conclusions:}

After the Momordica charantia L. studies, we could conclude that: there were obtained good effect results regarding the use of seeds treatment and watering treatment with colloidal silver aqueous solutions on the plants, as important aspect in development of an inovative method of organic fertilization.

After applying successive treatments with colloidal silver water solutions, from seed hydration to the end of the biocycle, we made analyes regarding mineral fruit content because that content could demonstrate the benefits of the tratement on the good development of the plants. So, we used atomic absorption spectrometry on dried fruits and the results were: the highest calcium concentrations were found in plant treated with colloidal solution 15 and $30 \mathrm{ppm}$ (V3 and V2); a good content of magnesium for V3 and V2 dried fruits; potasium content was the highest for V3 (30 ppm); Manganese and Iron content in the dried fruits was very good for V3 (30 ppm); high levels of Zinc was detected at V2 (15 ppm) and V3 (30 ppm).

Regarding the quantities of fruits harversted from each trawel, large amounts of fruits have been harvested from the plants of Momordica charantia L. treated with colloidal silver aqueous solutions at 15 and 30 ppm (V2 and V3).

We also made a germination study and we observe that the best germination was for V2 (15 ppm).

The final conclusion was that the results were favourable in the case of colloidal silver aqueous solutions with higher silver concentrations and the best version in the development of the plants was the one that aimed at their treatment with aqueous colloidal silver solution at a concentration of $30 \mathrm{ppm}-\mathrm{V} 3$.

This study represents a development point for the other next studied related with aqueous colloidal silver solution use on other interest plants. 


\section{INTERNATIONAL SYMPOSIUM "THE ENVIRONMENT AND THE INDUSTRY", SIMI 2018, PROCEEDINGS BOOK}

\section{References}

Agricultural Sciences, Available from: http:/agris.fao.org/agrissearch/search.do?recordID=RU2016001637. [20 March 2018].

Aqua Nano, Colloidal silver and the environment, Available from: https://www.coloidale.ro/index.php/en/colloidal-silver/53-centru-argint-mediu. [19 June 2017], in Romanian.

Council of Europe 2010, European Pharmacopoeia, Seventh Edition, Strasbourg, France.

Hans, L, Patrick E, Hayes, E, Laliberte, RSO \& Benjamin, LT 2015, 'Leaf manganese accumulation and phosphorus-acquisition efficiency', Trends in Plant Science, Elsevier, vol. 20, no. 2, pp. 83-90.

Ionescu, D, Popescu, M, Rizea, GD, Mihele, D, Bulearca, G, Ivopol, M \& Mihalcea, F 2014, 'Polyphenols and minerals, antioxidants in the plants used in the natural treatment of hepatobiliary disorders', Revista de Chimie, vol. 65, no. 5, pp. 507-511.

Nitech, Instruments, Available from: http://www.nitech.ro/pagini/noutati/tehnic/pginstruments-990fgf-spectrofotometru-de-absorbtie-atomica-514.html.

[22 February 2018]

Pennazio, S 2005, 'Mineral nutrition of plants: a short history of plant physiology' Rivista di Biologia, vol. 98, no. 2, pp. 215-36.

Popescu, M, Puiu, D, Mihalache, M, Bordei, N, Raiciu, AD, Cristea, I, Galaon, T \& Pascu, LF 2017, 'A study of the content in volatile oils and their composition of various aromatic herbs from ecological soils', 20th International Symposium "The Environment and the Industry", SIMI 2017, National Research and Development Institute for Industrial Ecology ECOIND, Bucharest, pp. 206212.

Popescu, M, Danciu, T, Danciu, E, Ivopol, G \& Manea, S 2011, 'Natural antioxidants, free-radical-scavengers and minerals, in fresh juices and vegetables', Revista de Chimie, vol. 62, no. 8, pp. 761-765.

Shapoval, OA, Mukhina, MT, Pryanishnikov, A, Klimov, AI \& Kudrinsky, AA 2015, Central Scientific Agricultural Library, Russian Academy of Agricultural Sciences, Available from: http://agris.fao.org/agrissearch/search.do?recordID=RU2016001637. [20 March 2018].

Volker, R \& Gabriel, S 2011, 'Iron transport in plants: Future research in view of a plant nutritionist and a molecular biologist', Soil Science and Plant Nutrition, vol. 50, no. 7, pp. 1003-1012. 